\title{
Applying the tools of complexity to the international realm: from fitness landscapes to complexity cascades
}

\author{
Robert Geyer and Steve Pickering \\ This is the final version submitted to CRIA. The definitive \\ version should be considered that published in Cambridge \\ Review of International Affairs,, Vol. 24, No. 1, March 2011
}

\begin{abstract}
Increasingly, complexity-based thinking is challenging the dominant rationalist, realist and reductionist international relations (IR) framework. However, to move this challenge beyond the academic realm and into the day-to-day world of policy, complexity thinkers must begin to develop useful tools for policy practitioners. This paper attempts to address this issue by demonstrating the weaknesses and limits of one traditional IR tool (X-Y graphic visualizations) and the strengths of complexity tools (the fitness landscape and range of complexity outcomes). To demonstrate these arguments we examine how fitness landscapes can be used to reinterpret traditional perspectives on development and conflict and make difficult problems more approachable through three-dimensional visualizations.
\end{abstract}




\section{Introduction}

Complexity-inspired thinking has been seeping into international relations (IR) for nearly 15 years, from the agent-based and network modelling work of Robert Axelrod (1997; 2006) and Lars-Erik Cederman (1997) to the more theoretical work of Robert Jervis (1998) and James Rosenau (2003) and the historical work of John Lewis Gaddis (2002). Meanwhile, others (Geyer 2003a; 2003b; Rihani 2002; Urry 2003) have been exploring the impact of complexity on different sub-fields of IR. We believe that the next step in exploring and evaluating the usefulness and efficacy of complexity for IR is to move debates to the more concrete level of examining particular complexity-inspired concepts and tools. To do so, this article will briefly review the dominance of the orderly, rationalist and linear framework of mainstream IR and then focus on exploring the potential of two complexity conceptual tools (fitness landscapes and range of complexity outcomes) ${ }^{1}$ on two sub-fields of IR: development theory and distance decay. These complexity conceptual tools were chosen because they have a powerful visual impact that moves one away from thinking of IR problems in 'flatlands'-linear two-dimensional patterns (Tufte 1990). ${ }^{2}$ Similarly, the two sub-fields of IR were chosen because they had strong traditions of 'flatlands' thinking and were therefore particularly apt for a review from a complexity perspective. In the conclusion, we argue that these tools can be useful, are an improvement on traditional IR tools for dealing with complex, emergent problems and can easily be applied to other sub-fields of IR.

\section{Order and IR theory}

Despite multiple waves of debate in modern IR, the dominant framework of academics and policy actors remains fundamentally orderly, rationalist and linear-at the pinnacle of which is realism/neo-realism. As Kavalski points out (citing the work of Hoffmann and Riley [2002] and Johnston [2005]):

Although most IR scholars would agree that the world of their investigations is complex, they would still insist that the

\footnotetext{
${ }^{1}$ To explore the broad range of complexity tools and concepts see Briggs and Peat (1990), Coveney and Highfield (1995) and Mitleton-Kelly (2003).

${ }^{2}$ As Tufte argues, 'Escaping this flatland [of two-dimensionality] is the essential task of envisioning information-for all the interesting worlds (physical, biological, imaginary, human) that we seek to understand are inevitably and happily multivariate in nature' (Tufte 1990, 12).
} 
proper way for acquiring knowledge about it is through the modelling of linear relationships with homogeneous independent variables that distinguish between discrete stochastic and systemic effects.

- Kavalski 2007, 446

This approach rests on a foundation of rationalism, bargaining, threats and opportunities, logical calculation and a belief in some combination of basic 'laws' of human interaction (Burchill et al 2001; Knudsen 1997; Moses and Knudsen 2007). Its intellectual 'tools', inspired by Newtonian mechanics and neo-classical economics (Beinhocker 2007; Bernstein et al 2000; Cîndea 2006), include: (a) modelling and visualization through causal and reductionist $X-Y$ graphical modelling, (b) a belief in and pursuit of stable endpoints and equilibria and (c) a faith in techno-rational decisionmaking. All of these three tools reinforce each other. If relationships are clear, knowable and rational then causal modelling easily applies and one can establish clear patterns and relationships. Given clear patterns and relationships, the path of history is revealed and clear endpoints are known and worked towards. Moreover, given these rational and knowable conditions and a clear understanding of the nature of the system and direction of historical development, then techno-rational elites and decision-making are the ideal actors for obtaining the best possible outcomes.

However, as has been seen time and time again, the world we live in is rarely orderly and causal. A quick glance at the unpredictability of the events of 11 September, uncertain implications of the 'war on terror', or dynamics of the current global economic crisis all show that the world is made of a complex mixture of order and disorder. These developments and others have brought IR theory to a state where it is particularly open to new concepts and ideas from the field of complexity. Comfort (2000) saw complexity as 'the greatest opportunity for creative change' in IR while Kavalski (2007) argued that it was forming the basis of a 'fifth debate' in the history of IR by creating a 'cross-pollination between natural and social sciences'.

However, the link between academic debates and policy actors and action is not particularly clear. Though ideas of complexity may have filtered into the policy world, it is still undoubtedly dominated by the basic concepts and tools of rationalism and realism. In fact, with a growth of audit-based public policy, such as New Public Management (Blackman 2001; Power 1997; Scott 1998), rationalist policy approaches and tools seem to be in the ascendant once again (particularly in the UK). In addition, the political discourse of popular IR remains dominated by a simplistic bipolar vision of 
global reality, terrorists vs. anti-terrorists replacing the earlier communists vs. anti-communists. Hence, if complexity is going to have a real impact on IR it has to go beyond the academic debate and start exploring how its core concepts and tools can be used in a practical and policy-oriented manner.

\section{Visualizing causality (X-Y graph) vs. visualizing complex- ity (fitness landscape)}

The classic mental model for visualizing linear causal relationships is the standard two-dimensional $X-Y$ graph. Though non-linear outcomes can also be represented on an $X-Y$ graph, from an orderly perspective, ideally all human systems should be capable of being plotted in a linear fashion on an $\mathrm{X}-\mathrm{Y}$ graph and policy actors are strongly encouraged to visualize their policy problems in these terms. In IR, quantifiable causal modelling has been a central tool ever since 1945. Arguably, the most influential example of this type of analysis and visualization can be found in the work of the esteemed academic and advisor to US President Kennedy, Walter Rostow.

Rostow's most influential work, The stages of economic growth: a noncommunist manifesto, written in 1960, set the core framework for the influential IR sub-field of development theory and policy.Later, Rostow attempted to extend his 'stages' thinking to politics, hoping to make the 1970s 'the Decade of Political Development in something like the sense that the 1960s has been the Decade of Economic Development' (Rostow $1971,5)$. As is well known, in that work he laid out the five main stages of development (traditional, ${ }^{3}$ preconditions for take-off, take-off, drive to maturity and high mass consumption), epitomized by the development of the US. Though he never graphically represented these stages in his book, their visualization on an $\mathrm{X}-\mathrm{Y}$ graph was obvious.

For Rostow, despite various caveats and a recognition of the complicated nature of economic development, ${ }^{4}$ the development process had an underlying clear linear progression with an identifiable endpoint (mass consumption society), 'the process of development now going forward in

\footnotetext{
${ }^{3}$ It is very interesting to note that Rostow identified this 'traditional' stage as a 'preNewtonian' stage where humans had yet to conceive of their 'physical environment as subject to knowable and consistent laws' (Rostow 1990, 90).

${ }^{4}$ Interestingly, in a coda to the third edition of The stages of economic growth (1990) Rostow explored the implications of non-linear thinking on his classic work and concluded that 'The Stages is congruent with the insights of non-linear dynamics' (Rostow 1990, 258).
} 
Asia, the Middle East, Africa and Latin America as analogous to the stages of preconditions and take-offs in other societies' (Rostow 1990, 139). In essence, by viewing developing countries as fundamentally linear systems that needed to move up the developmental ladder and stay on track (avoid communism), one could then apply basic mechanical strategies. As with any mechanical system, in order to increase its output: add more energy to the system, improve the parts of the system, promote the better working parts of the system and eliminate malfunctioning parts.

In order to do this Rostow suggested three policy strategies for those states moving through the preconditions and take-off stages in order to maintain democratic development and a Western orientation. These strategies clearly mirror a linear mechanical vision:

- 'potentialities of external assistance must be organised on an enlarged and, especially, on a more stable basis' (Rostow 1990, 142).

- Foreign aid equals energy, therefore more aid will make the system develop faster.

- 'potentials of known technology . . . must be brought to bear' (Rostow 1990, 143).

- Technology will increase the efficiency of the system, therefore more technology will make the system develop faster.

- local 'non-Communist literate elites' (Rostow 1990, 144) must provide appropriate leadership and policies.

- Appropriate actors will improve the system, therefore developing and promoting those actors and blocking/eliminating inappropriate actors will make the system develop faster.

For Western policy actors, the implications were clear: increase and stabilize foreign aid, encourage large-scale technology transfers and maintain high levels of political/diplomatic/military intervention in local politi$\mathrm{cal} /$ social/economic structures to support appropriate local elites.

Moreover, for Rostow, writing during the height of the Cold War when the emerging independent nations of the Third World were key regions of dispute between the East and West, one could clearly see that, in addition to any humanitarian concerns for the developing world, Rostow's book was an attempt to produce a linear counter-model to Karl Marx's four stages of development (feudalism, capitalism, socialism, communism) as well as a 
Figure 1: Rostow's stages of economic growth, represented on an $X-Y$ graph

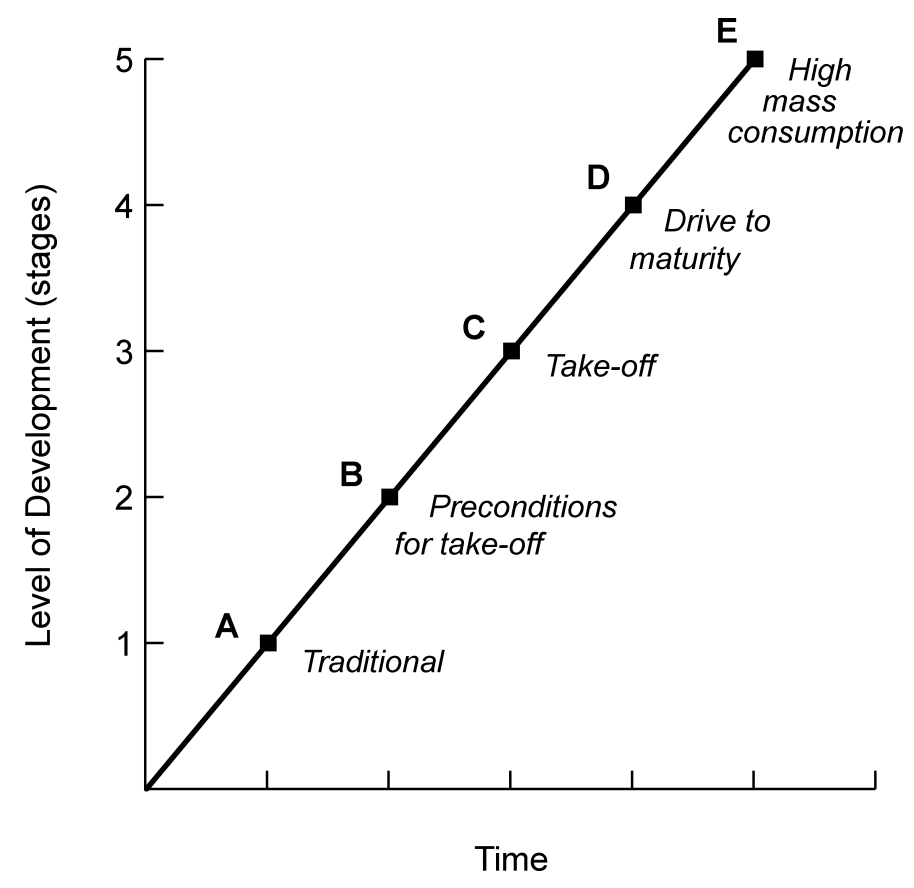

guide to avoiding 'communism: the disease of transition' (Rostow 1990, 162). For Rostow, this 'disease' 5 was particularly problematic during the stages of pre-take-off and takeoff. Hence, policymakers had to be extremely vigilant and interventionist with states passing through this stage. Visually, this could be represented as in Figure 2.

This framework generated a number of disturbing implications:

- There is an endpoint $\mathrm{E}$ (or in the communist case $\mathrm{F}$ ). The goal is to get the developing country there fast and stay there. Any strategy that gets countries to $E$ faster must be better.

- Any strategy that keeps countries on the $A$ to $E$ line longer must be better and any that moves them up faster must be better. The end justifies the means.

- Having extensively studied the model, other comparable cases and the idealtypical model of development (the US), Western experts can

\footnotetext{
${ }^{5}$ This metaphor of communism as disease was also used by George Kennan in 1946 in his famous telegram to President Truman.
} 
know how to get countries from A to E. The key is to identify where the developing country sits on the developmental path and apply appropriate policy inputs.

- Local knowledge, actors and opinions are of secondary importance. In fact, buffering the Western experts from their mistaken, misguided and short-term views may be essential.

- Local actors should be fundamentally passive. TheWestern experts know how to move the system towards $E$ as fast as possible. Hence, local actors should do as they are told and repeat the experts' strategies as much as possible. If something goes wrong, repeat previous strategies or refer back to Western experts. Experimentation, exploration and learning are best avoided and serve only as a last resort.

- In general, failure to move from $A$ to $E$ quickly or falling off the $A$ to E line (drifting to communism!) implies a failure to follow the rules of development. For the Western expert, this situation calls for even more intensive efforts through greater aid, technology and intervention. For the local actor, it implies that your society is a particularly backward and problematic one and that you should be increasingly passive and accepting of external intervention.

\section{Plus ça change, plus c'est la même chose}

Though extremely popular with policymakers, Rostow's thinking did not go unchallenged in academic circles. In fact, most of the major development economists and international political economists (Gunnar Myrdal, Simon Kuznets, Alexander Gerschenkron, Robert Solow) took part in the debate over Rostow's work (Rostow 1963). However, despite these challenges (and later ones: structuralist, dependency and basic needs approaches) mainstream development policy and approaches remained remarkably linear and wedded to a belief in clear causal relationships. In the 1970s, 1980s and 1990s with the rise of the debt crisis in the much of the developing world the goal shifted from creating 'mass consumption' societies to 'free market' societies. A new linear development path was developed that positioned all developing countries along a path towards full free market development, and appropriate universal policy strategies (labelled 'structural adjustment'-reduce state expenditure, balance state budgets, privatize state industries, open up to international trade) were 
Figure 2: States succumbing to communism during pre-take-off/take-off

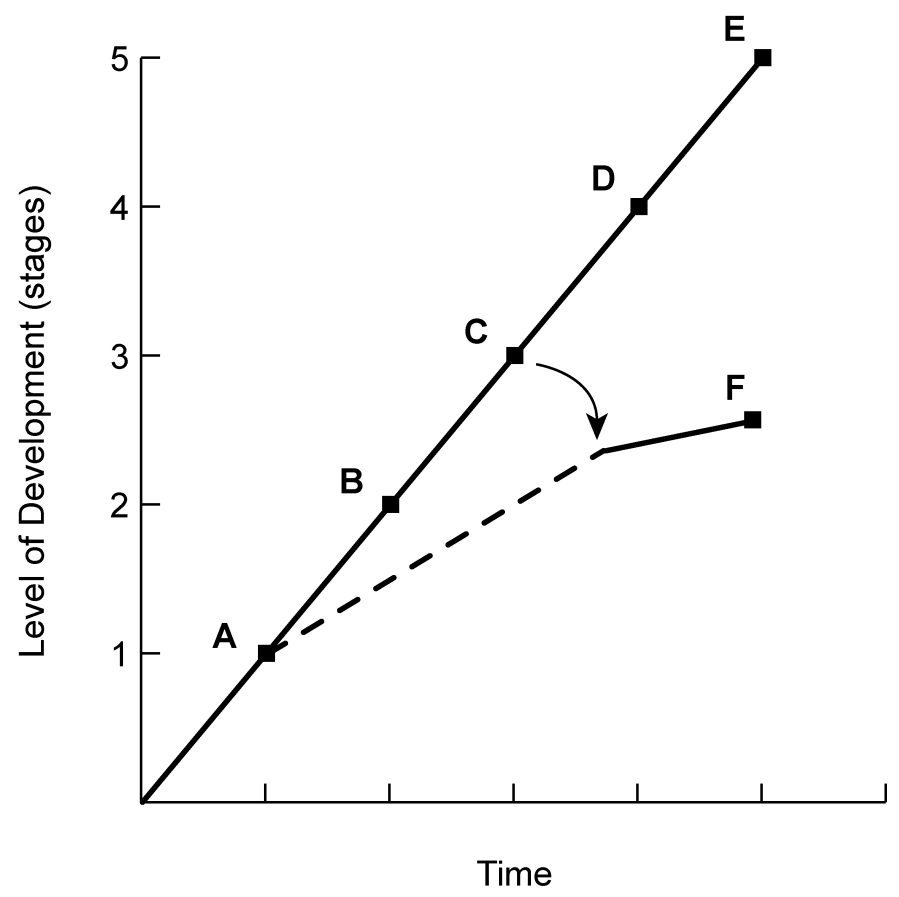


developed (George 1991; Kosack et al 2005) In essence, one X-Y vision of the future was replaced by another.

However, as pointed out by the Cambridge economist Ha-Joon Chang, this free market goal/vision upheld by the International Monetary Fund (IMF)/World Bank and backed by major Western powers reflected neither the reality of advanced industrial states (which maintained extensive state sectors, used Keynesian economic strategies and had large statesupported social services) nor the means by which the advanced countries attained their wealth and position. As Chang notes, 'Britain and the US are not the homes of free trade; in fact, for a long time they were the most protectionist countries in the world ... the best-performing economies have been those that opened up their economies selectively and gradually' (Chang 2007, 17).

Major international policy actors (World Bank, IMF, UN) were aware of the failure and inconsistencies of these plans (Dollar and Svensen 1998; World Commission on Environment and Development 1987). The problem was that so long as they remained locked into a linear framework, visualized by the $X-Y$ graph, they constantly returned to variations of the same underlying strategy. In essence, since the framework is assumed to be correct, but the strategy didn't work then to make it work, the system needs (a) more energy/money and/or (b) improved inputs and/or (c) increased control over the local actors, as William Easterly, a former employee of the World Bank, makes abundantly clear in the repetitive quotations presented in Table 1.

As Easterly goes on to argue, the 'lack of historical memory in the aid community... (and) the unchanging approach to many of these desirable objectives shows again that aid agencies keep throwing in more and more resources to try and reach a predetermined, although unattainable, goal' (Easterly 2006, 200). Most recently, as pointed out by Easterly, this type of thinking leads to a form of 'postmodern' imperialism for persistently 'failed states' (Iraq, Afghanistan, Sudan, etc). This position, outlined in various articles in the influential journal Foreign Affairs, has significantly influenced current US foreign policy towards these states. As the academic Stephen Krasner, who became a policy advisor to the US State Department in 2005, argued:

In the future, better domestic governance in badly governed, failed, states and occupied polities will require the transcendence of accepted rules, including the creation of shared sovereignty in specific areas. In some cases, decent governance may require some new form of trusteeship, almost certainly de facto 


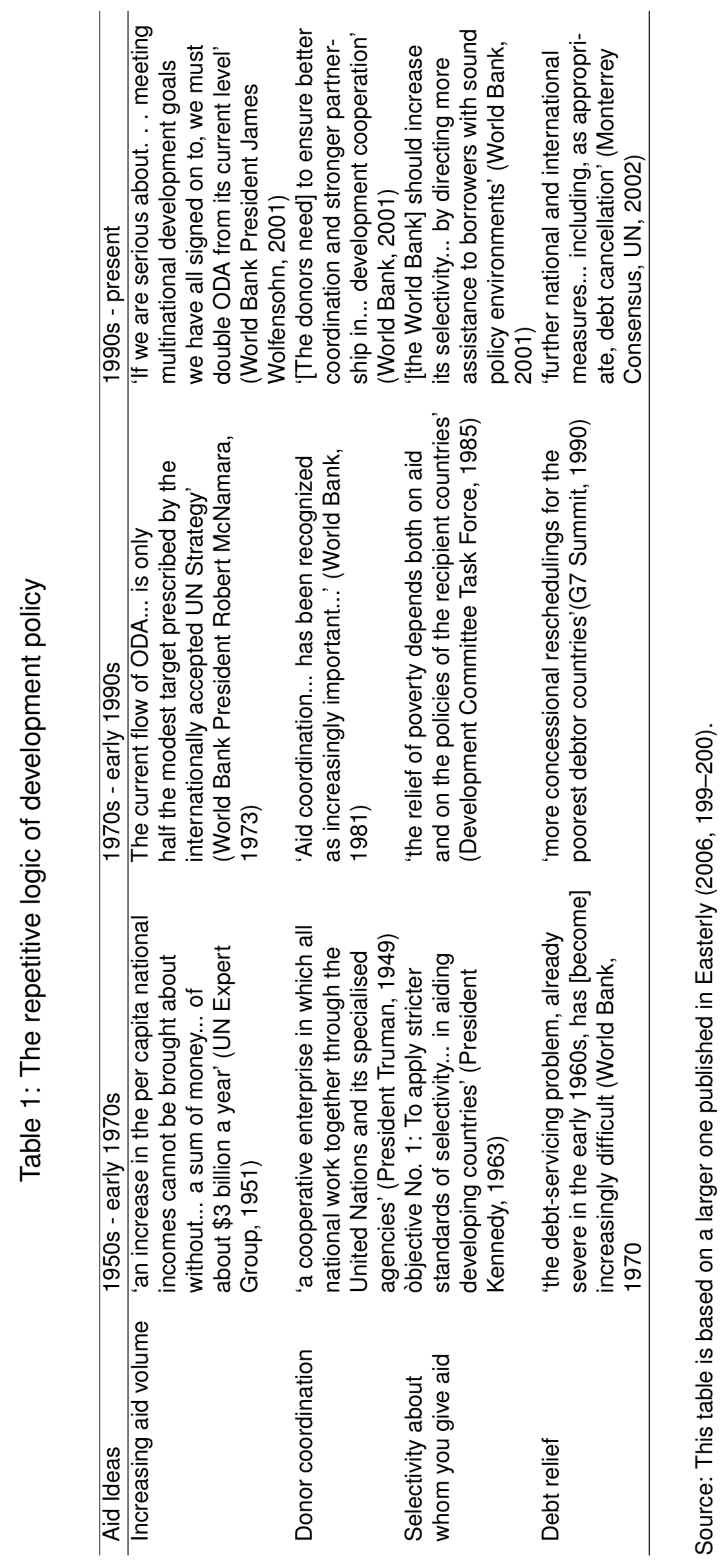


Figure 3: Different visions of the future

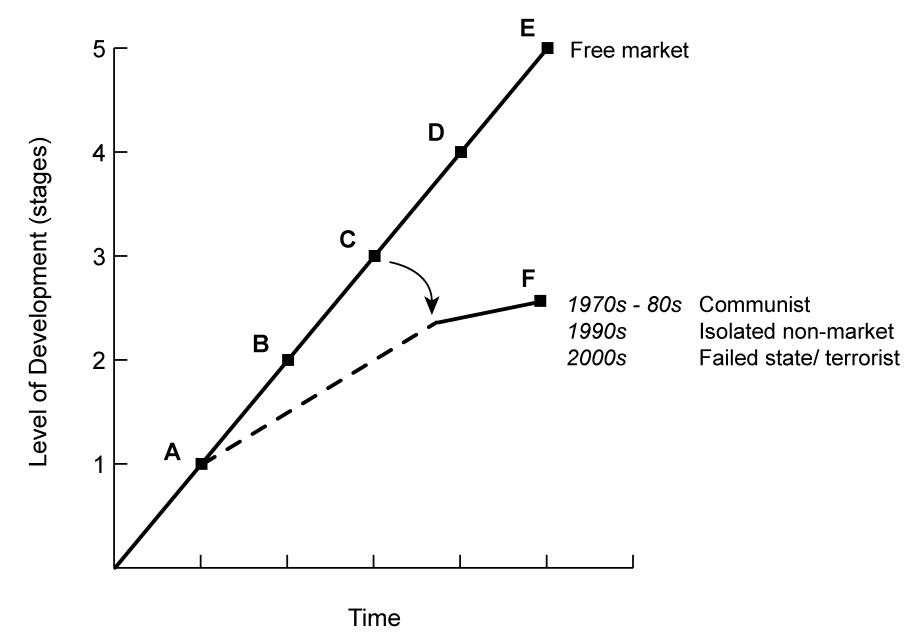

rather than de jure.

- Krasner 2004, 85

From this perspective, as outlined in Figure 3, the framework of linear development remains, the key crisis period stays the same, and the only difference is the perceived negative endpoint. In the 1960s and 1970s it was 'communism', in the late 1980s and 1990s it was 'non-free-market states' and in the 2000s it became 'failed states'.

\section{A different point of view: the fitness landscape}

For simple orderly phenomena and systems, the $X-Y$ graph is an excellent tool. To visualize and calculate the movements of balls on a table, the trajectory of missiles, etc. the X-Y graph is all you need. However, for complex systems you need a way of modelling and imagining a system that can move in varying and unpredictable ways over time. You need a way to show the probability of a system to move in a multitude of directions, a way to show how the system 'fits' with varying situations and circumstances. You need a fitness landscape.

Fitness landscapes were originally designed by population and evolutionary biologists and used in a variety of modelling applications (Coveney and Highfield 1995; Kauffman 1995), and are mathematically represented on a threedimensional X-Y-Z graph. In this three-dimensional visualization, valleys represent areas of poor fitness, mountains represent high fitness 
and flatlands represent areas of neutral fitness. ${ }^{6}$ In other words, biological complex systems, such as schools of fish, herds of buffalo, or entire species, are constantly moving through an evolving fitness landscape where new predators, food sources and numerous other factors combine to influence their chances for survival. Some of the basic rules for survival on a fitness landscape are adaptability, flexibility, learning and balance.

For example, for our herd of buffalo if a new more nutritious grass began to grow on their normal grazing land the fitness landscape of the herd would improve, more buffalo would adapt to the new situation by eating more of the nutritious grass and over time the population would increase. However, the increasing numbers might overgraze the new grass (which could take longer to recover than older grasses) and the fitness landscape for the herd would now be 'poor'. The herd might attempt to adapt to the new 'landscape' by searching for new grazing areas or if the herd remained in the same area the population might decline. Fundamentally, as long as the 'system' survives, the fitness landscape continues to evolve through time like a never-ending conveyor belt.

Obviously, it does not take much of an imaginary leap to see how fitness landscapes relate to the situations of human complex systems. To begin, imagine a landscape that is full of flatlands, valleys and mountains and stretches endlessly into the future. Now, imagine that the valleys represent zones of poor performance, the mountains are zones of good performance and the flatlands are areas of neutral performance. Moreover, imagine that the further you peer into the future the hazier the detail and definition of mountains, valleys and flatlands become.

\section{Linear versus complex outcomes}

Now before we go into our case studies, we need to clarify one other key difference between the linear X-Y graph and fitness landscape visualizations. As we saw in Figures 1-3 above, the outcomes of our linear $X-Y$ visualizations had a strong either/or character. The developing country was either on track (progressing towards the proper endpoint, mass consumption society, etc.) or off the track (heading to communism). It was either making progress or it was stagnant. It was either a success (an example for others to follow) or failure (in need of more aid, technology and external intervention). This represents a much larger and deeper trend in social science and public policy: the belief in the creation of human order,

\footnotetext{
${ }^{6}$ Equating up with fitness and down with lack of fitness is an arbitrary designation. It could easily be reversed, as Gell-Mann (1994) does.
} 
which can be traced back through the works of Hegel, Condorcet, Bacon and beyond. Basically, since nature is fundamentally orderly, then humans must be as well. The key for the social sciences and public policy actors is to eliminate disorder and uncertainty and to create greater order. From this perspective, viewing society and public policy as an evolving balancing act between emerging order and disorder is an admission of intellectual and policy failure.

On the other hand, from a complexity perspective, humans must constantly seek the appropriate balance between order and disorder in their symbiotically evolving environment. Acting on and in an evolving complex system that changes with their own actions, individuals' and groups' choices become more uncertain the more detailed they become. At an individual level, we know that we must remain active to stay healthy, but which kind of activity is best for us and do we find most enjoyable? For a particular school, it must certainly cover the basic educational needs of its pupils, but what types of specialisms should it have and are these the most relevant to the needs of the larger community? At a national policy level, maintaining a competent police force is a necessary policy, but what combination of local and centralized policing structures is the best and how should the force be structured to meet the different needs of ru$\mathrm{ral} / \mathrm{urban}$ communities? At the international level, observing international law is generally a good thing. But will allowing a convicted terrorist bomber to return to their home country based on compassionate legal principles (Scotland's release of the Lockerbie plane bomber to Libya in August 2009) significantly undermine Scottish relations with the US or will the incident be forgotten in a post-summer haze? In essence, policy actors must continually strive for the zone of creative complexity on a broad range of potential outcomes. In a very simplistic fashion, this range can be represented as in Figure 4.

In contrast to the linear $X-Y$ perspective, the most difficult areas for complex systems to survive in are in the realms order and disorder. In a realm of strict order, actors are stripped of their ability to make local decisions, freely interact and respond to emergent developments in new ways. This is the zone of the most rigid authoritarian and totalitarian regimes where virtually every major aspect of life is structured (USSR under Stalin, Cambodia under Pol Pot, Afghanistan under the Taliban, etc). Likewise, the realm of disorder is one where human actors struggle to make any local connections or interactions because they are so unpredictable. Periods of extreme social disorder or civil war, where all trust evaporates in a cloud of fear, are key examples (Rwanda, Sierra Leone and the Sudan in the 1990s are all recent examples). 
The realms of stifling order and destructive disorder are much more common and can provide stable outcomes for complex human systems. Under stifling order, for example, central actors apply overly rigid criteria upon local actors who are forced to fulfil these criteria to the detriment of obvious local problems and opportunities, for example when a particular ethnic, social or gender group is only allowed to perform certain social or economic tasks (untouchables in India, women under strict Islamic law, etc). Equally negative outcomes can occur under destructive disorder. In this case, the system lacks a clear structure or suffers under constantly shifting rules. The political fate of the Iraqi people struggling to cope in the aftermath of the US occupation is a clear example.

The realm of creative complexity is generally the most productive for human systems. It combines a stable evolving framework that establishes core boundaries with as wide a variety of local interactions as possible. Systems in this realm have a general direction, but are not rigidly locked into a particular pathway. As explained by the economist Ha-Joon Chang (mentioned above), all of the successful advanced industrial economies have adapted, shifted and responded to evolving conditions throughout their economic development. A combination of external and internal factors has allowed them to explore, make mistakes, learn as they went along and balance within the realm of creative complexity for lengthy periods of time.

In opposition to the implications of the linear framework, a complexity framework has a number of commonsensical implications:

- There is no endpoint to a fitness landscape nor is there any final resting point. The primary goal and tactic are adaptation and balance to changing circumstances.

- The main actors on treks on the fitness landscape are the actors/countries/ societies themselves. They are actively moving through the landscape and making essential choices. Their opinions, experiences and learning matter. External experts are secondary.

- External intervention is always problematic. In general, the simpler it is, the higher the probability of success (if a population is starving send in food aid). The more detailed and complicated the intervention, the lower the likelihood of success. The US's attempt to restructure the entire political system of Iraq in 12 months after the fall of Saddam Hussein is a prime example.

- Learning is essential and never stops. Being aware, making choices, experimenting, exploring is how an individual, institution or country 
Figure 4: Range of outcomes

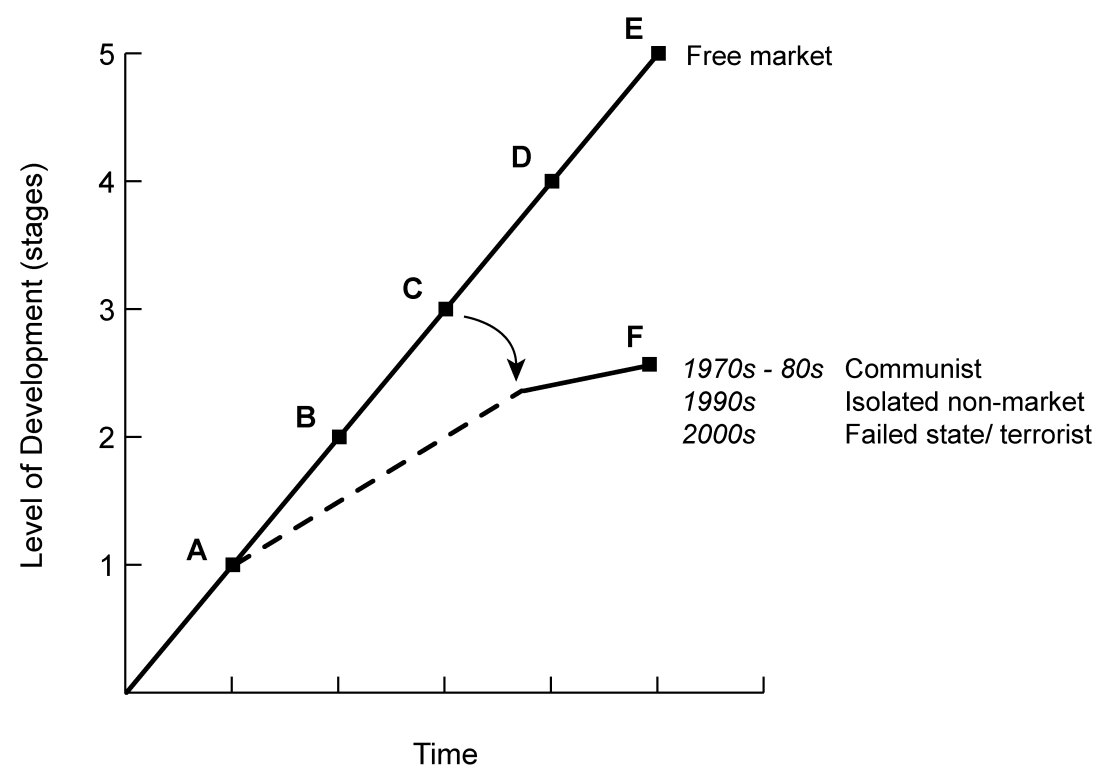

learns about their particular landscape and evolve tactics for dealing with the inevitable unknown.

- Mistakes, misdirections and occasional stumbles into valleys of low fitness are normal and not a mark of weakness/failure, a lack of development and/or inferiority. The only mistake is refusing to see them as normal and not learning from them.

- Change is normal. Desperately repeating the tactics of the past (or of other more successful states/nations) is no guarantee of future success.

\section{Case study one: a fitness landscape for development}

As we have argued above, the post-1945 development project, despite various revisions, seeks to guide a nation, or community, 'in need of development', along a predetermined path, with supposedly clear signposts that have been charted by earlier pioneers, to a specified end-state of 'development'. The country to be developed is positioned on a certain level on the development ladder and appropriate policies are applied until it reaches the 'equilibrium' point of the fully developed countries. Once there it is 
Figure 5: A fitness landscape view of development

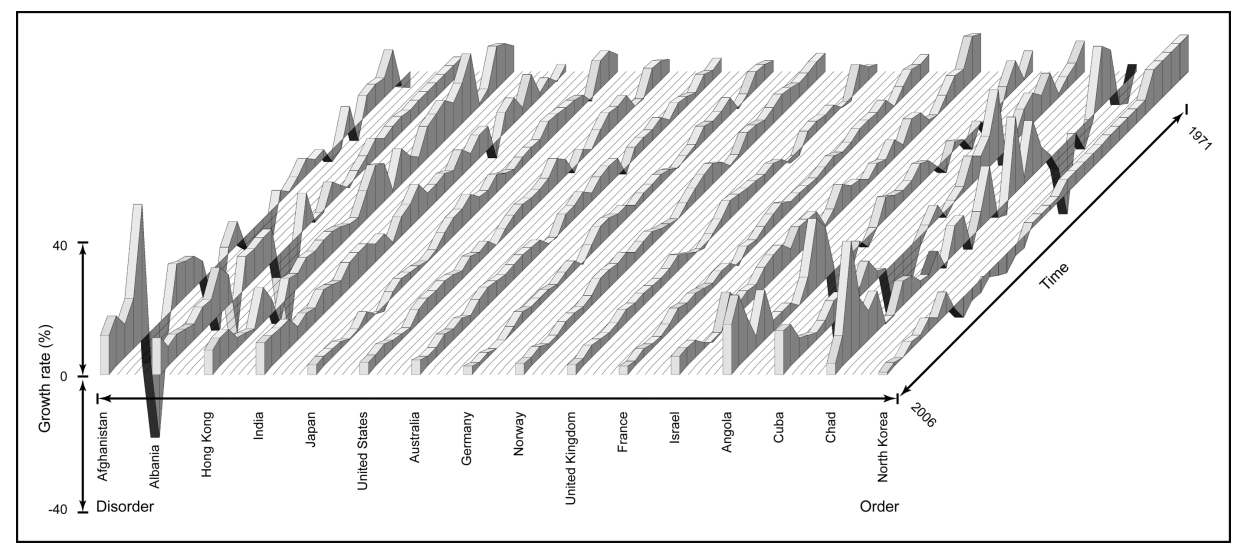

then stable and in the words of Francis Fukuyama, it has reached the 'end of history'.

However, as the mixed results of development plans and aid demonstrate, development is not a linear process and even the currently successful countries used a variety of directions/policies/institutions/cultures and created, over lengthy periods of time, distinctive outcomes that can be generally packaged as 'developed'. A linear $\mathrm{X}-\mathrm{Y}$ graph could hardly be used to present an illustration of that concept of development. Visually and metaphorically, the next step away from traditional thinking is to visualize development occurring on a threedimensional fitness landscape such as is shown in Figures 5 and $6 .^{7}$

In these basic fitness landscapes, ${ }^{8}$ we combined three factors:

\footnotetext{
${ }^{7}$ Both figures were originally published in Geyer and Rihani (2010, permission was kindly granted for a reprint of the images by the publisher). Please note, that in order to avoid data overlap, the figures for state expenditure as a percentage of GDP were averaged for the 1971-2006 period, creating the impression that the relationship did not change over time. Interestingly, in the case of our advanced industrial countries, the relationship was generally remarkably stable. Unsurprisingly, the least successful economies often fluctuated wildly.

${ }^{8}$ It should be noted that our fitness landscapes presented in Figures 5, 6 and 11 are not fitness landscapes as defined by Stuart Kauffmann (1995) and others. In their definition, the fitness landscape examines the interrelationship between the factors influencing the fitness of a particular actor or set of actors in a given state/system. In our simplified fitness landscapes, though we use a three-dimensional structure, there is no direct interrelationship between the countries and their economic performance or the level of conflict that they experience. Hence, we are unable to examine the interrelationships that create this particular three-dimensional outcome. However, as a metaphorical tool for
} 
Figure 6: Another fitness landscape view of development

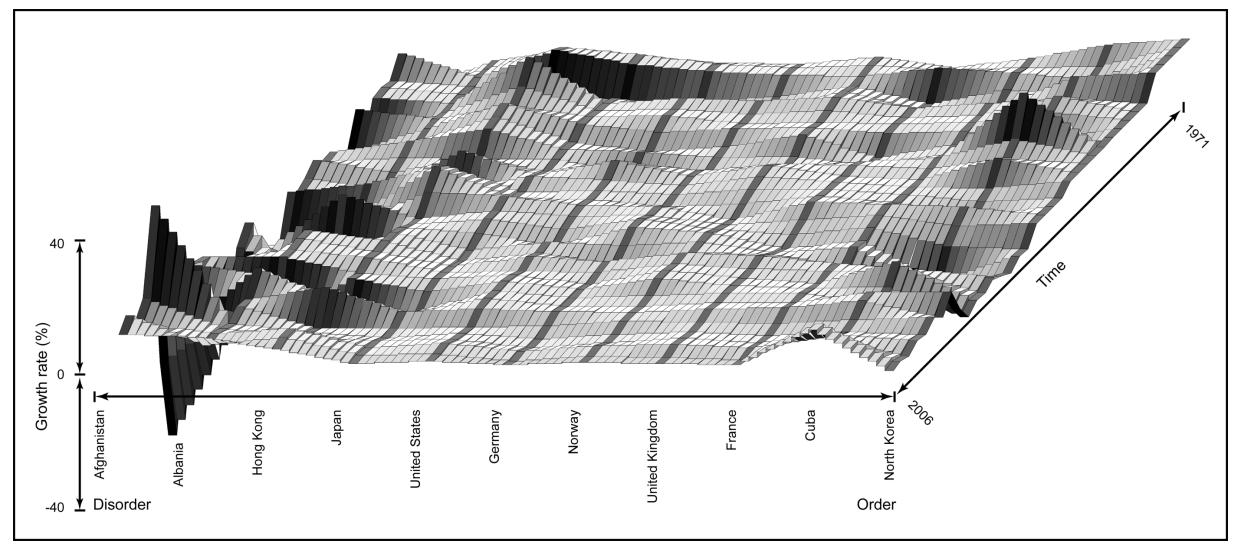

- (X axis) Annual growth rates (reported by the UN National Accounts).

- (Y axis) A simplistic range of how disorderly-orderly the society was. To generate this disorder-order scale we used the UN National Accounts and looked at state expenditure as a percentage of gross national product (a very general indication of how much the state controls the economy). The more state control, the more order. The less state control, the less order.

- (Z axis) Time, 1971-2006.

Obviously, this is only a very rough indication of how much a society is held in an orderly state or caught in a disorderly conundrum. Nevertheless, some very revealing patterns emerged.

For the successful advanced industrial countries:

- Unsurprisingly, they tended to be bunched towards the middle, exhibiting a mix of state-market/order-disorder (avoiding extremes of order or disorder).

- Interestingly, despite their being in the middle, there is a remarkably broad range of market-state and disorder-order variety. For example, Sweden (on average) has nearly twice as much state dominance of the economy as Japan and almost three times as much as Hong

moving away from traditional linear interpretations we believe that these simplified fitness landscapes are valid and conform to a general complexity framework. 
Kong. Hence, as many others have argued, there is no single road to success, but a wide variety of strategies.

- Moreover, for most cases, the key to success is continual small-scale improvements over long periods of time. As the data show, with some famous exceptions, there is no 'rush for growth'.

For the less successful countries:

- Being too orderly or disorderly can be equally bad. On the orderly extreme, North Korea reported reasonable growth rates until the mid1970 s and then went into a steady decline as it became more and more rigid and less and less capable of successfully interacting with the increasingly globalized world.

- At the other end of the spectrum in Afghanistan, where there is a lengthy history of civil division and strife and almost constant war since the late 1970s, growth rates fluctuate wildly with the constantly changing security situation.

- Unsurprisingly, both of these cases score very poorly on Transparency International's rating of corruption indicators. (See http://www. transparency. $\operatorname{org} /$.

- Lurching from one extreme to the other creates the worst possible of all worlds. Iraq was caught in a zone of stifling order under the regime of Saddam Hussein, who (inadvertently aided by the UN embargo) rigidly dominated all major aspects of the Iraqi economy. Subsequently, despite the successful US-led invasion of 2003 and huge efforts to develop the country, it fell into a zone of destabilizing disorder.

What are the general implications of this re-imaging of development from a complexity perspective? First, development is revealed as a process of exploration with a desired general direction in mind. There are some rules to follow: create a stable institutional framework, encourage decentralized interactions, avoid civil strife and a stifling state structure, etc. There is no perfect or aggregate pattern for exactly how a country should stay within these boundaries. Hence, detailed prescriptions of what should be done in the long term are likely to be ineffective or counterproductive. Moreover, from a complexity framework, the development project will set out to improve a nation's performance within continually shifting conditions by means of enhancing its members' fitness and capability. The process is ongoing and the outcome is not preordained. 


\section{Case study two: complexity and distance decay}

Another aspect of IR theory which can benefit from the complexity approach is the concept of distance decay. This idea was used widely during the Cold War not only in IR theory but also in economics (Isard 1956; Tinbergen 1962; 1965; Cobb and Elder 1970; Hughes 1972; Merritt and Clark 1977). The study of the effect of distance on conflict goes back to antiquity, ${ }^{9}$ but more recently, as new datasets have become available, there has been a renewed interest in the notion of distance decay (Gleditsch and Ward 2001; Buhaug and Gates 2002; Murdoch and Sandler 2004; Robst et al 2007; Hegre 2008). Distance decay is a useful concept, but complexity can help us to understand some of its strengths and limits.

\section{Boxers, neighbours and boils}

The basic reason why distance is considered to be such an important variable in conflict research can be reduced to three analogies: boxers, neighbours and boils. Bremer expressed the boxer argument in its simplest form: 'Boxers, after all, cannot fight until they are physically able to reach one another' (Bremer 1992, 312). Wesley used a neighbour analogy to develop the theory of interaction opportunities, 'A man is much more likely to quarrel with his next-door neighbor than with someone several houses removed. Interactions of all sorts, both constructive as well as destructive, are more frequent between people in adjacent areas than those widely separated geographically' (Wesley 1962, 387). Wesley extended this argument to a geographically deterministic extent, arguing that 'the frequency of wars and the size of wars may be derived on the basis of geographical opportunity alone' (Wesley 1962, 387). Finally, Zipf utilized the boils analogy in his Principle of least effort: 'If we listen to proverbs, "a boil on your own neck will worry you more than a famine in China'; yet as your location is ever nearer to China, the comparative magnitude of your worry about the famine will increase proportionately-even to the point that the boil is forgotten' (Zipf 1949, 391).

Many theorists approaching IR from a geopolitical perspective regarded

\footnotetext{
${ }^{9}$ For Sun Tzu, distance was one of two factors to consider in determining the impact that 'ground' would have on the success of a military campaign; the other was rugged or mountainous terrain. Indeed, distance and terrain are two sides of the same coin: Sun Tzu's commentator, Ho Yen-hsi, tells us that "Ground" includes both distances and type of terrain' (Sun Tzu 1963, IV.18). Clausewitz (1968) went on to spend four chapters of On war looking at the military implications of mountainous terrain. Rugged or mountainous terrain is very closely related to distance, but it is beyond the scope of this paper.
} 
Figure 7: Boulding's loss of strength gradient. Notes: Left is based on Boulding (1962, Figure 12.2, p. 232); right increases distance between A and $\mathrm{B}$.
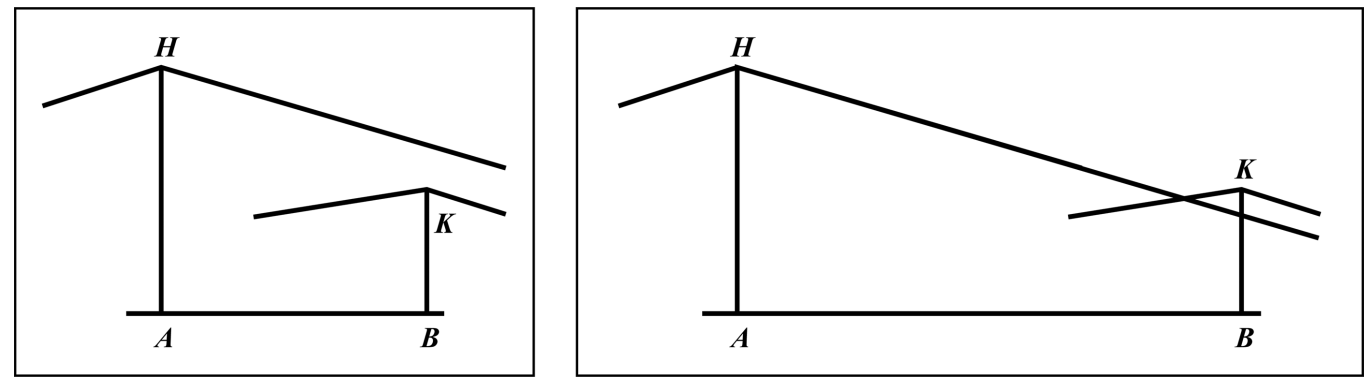

distance as being perhaps the single most important variable in understanding conflict. Spykman argued that 'power is effective in inverse ratio to the distance from its source' (Spykman 1942, 448). Similarly, George Kennan made the case that 'the effectiveness of the power radiated from any one national center decreases in proportion to the distance involved' (Kennan 1961, 276). The most referred to visual representation of this idea is Boulding's (1962) loss of strength gradient (LSG), reproduced in Figure 7.

In these two versions of Boulding's Figure 12.2, A and B are states; the heights of the lines $\mathrm{H}$ and $\mathrm{K}$ represent the power of those states. The diagonal lines represent the decline in power as distance from the states increases. If we consider the two states to be India and Sri Lanka, the lefthand diagram shows that India is always stronger than Sri Lanka, even in Sri Lanka's home base. However, in the right-hand diagram the distance between the two states is increased: imagine that Sri Lanka was suddenly moved to the Pacific Ocean. Now, although the absolute power of the two states has remained the same, the relative power has changed: India is no longer more powerful than Sri Lanka in Sri Lanka's home base.

Yet it has been long realized that regarding distance decay as purely linear was too simplistic. Even Boulding, though arguing that 'deviations from linearity are not likely to be great' (Boulding 1962, 231), admitted that loss of strength lines would not always be straight. Later, Wohlstetter pointed out that the effect of distance is 'very much more complex than is recognized by linear theories of the weakening of strength with distance' (Wohlstetter 1968, 252). Nevertheless, a simple, linear view of the importance of distance continued to dominate the field. As O'Loughlin, long a critic of simple geographic determinism, pointed out in 2000, 'For the IR 
modelers, the world had effectively become a billiard-table, an isotropic geopolitical plain, but at a cost' (O'Loughlin 2000, 7).

To understand the importance and attraction of such thinking consider the map (Figure 8) presented in Iraq's weapons of mass destruction: the assessment of the British government (British Government 2002), also known as the infamous 'dodgy dossier'. There is nothing distinctive about this map. It is similar to a multitude of force/power maps that can be found in a range of post- 1945 policy documents and academic papers. Here, one sees four distance bands, each indicating the idealized maximum range of five different types of missile. For what it does, the map is correct: the isobars give a reasonably accurate indication of the parts of the world which could be reached by a missile capable of travelling 150,650, 900 or $1200 \mathrm{~km}$ from within the territory of Iraq. However, even this relatively simplified system (achievable distances of certain types of missiles) ignores a range of complex variables, including weather patterns, variety and position of targets, weapons imprecision, etc, that could significantly affect the actual missile range outcomes. More importantly, this simplified map had a second goal in the context of the 'dodgy dossier'. It was designed to clearly demonstrate the expanding and extensive range of Iraqi power and the subsequent need to contain and limit that power. In essence, a linear tool was used to simplify a complex power situation in order to justify later intervention.Without a proper recognition of its limits, a linear LSG tool is open to significant misuse and misinterpretation.

This does not imply that the LSG is no longer viable or useful or that it cannot be used in complex situations. However, one must recognize its limits. For example, recently Buhaug made the first application of the LSG to civil war. He refined the notion of just using lines in the LSG to represent distance; for him, such lines represent 'not only geographic distance but all sorts of factors that might affect the LSG, including type of terrain, level of infrastructure and logistics capabilities, extent of local support, cultural dissimilarities, and morale' (Buhaug forthcoming, 6). However, on a practical level, he found that data restrictions mean that a simple geographic proxy had to be used. This led Buhaug to use the visualization shown in Figure 9.

In this case, $G$ represents the home base of a government (the capital city), while $\mathrm{R}$ represents the base of a rebel group. In the left-hand diagram the government is assured of military victory, while in the right-hand diagram the rebel group's relative strength is greater than the government's; indeed, its strength is greater than the government's at all points to the right of $E$, which represents equal strength.

We would like to take this visualization of the data on civil conflict one 
Figure 8: 'Current and Planned/Potential Ballistic Missiles,' originally presented as Figure 7 in Iraq's Weapons of Mass Destruction: The Assessment of the British Government (British Government 2002, 31).

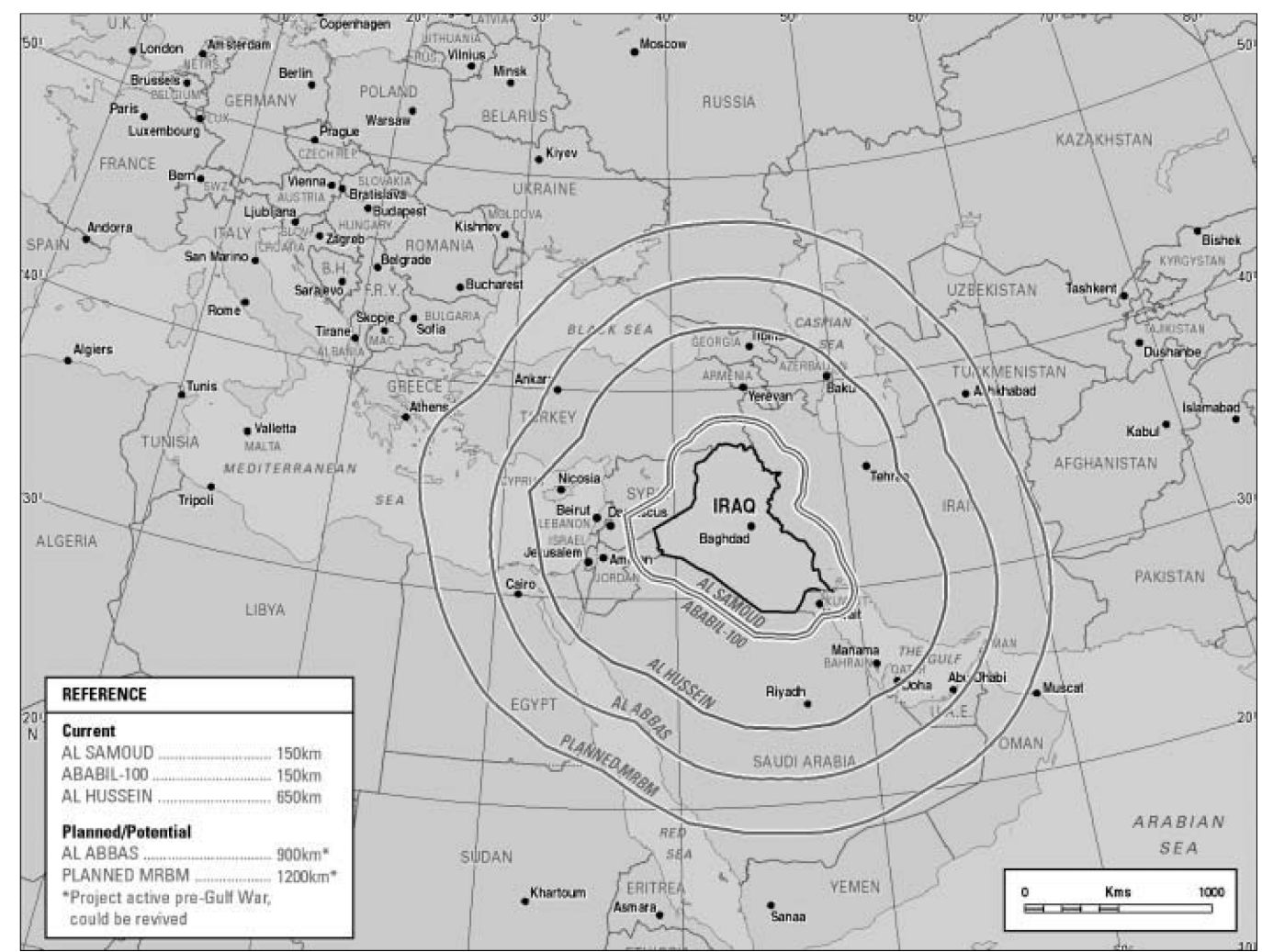

Figure 9: Buhaug's application of the LSG on a civil basis (originally presented as Figure 1 in Buhaug forthcoming)
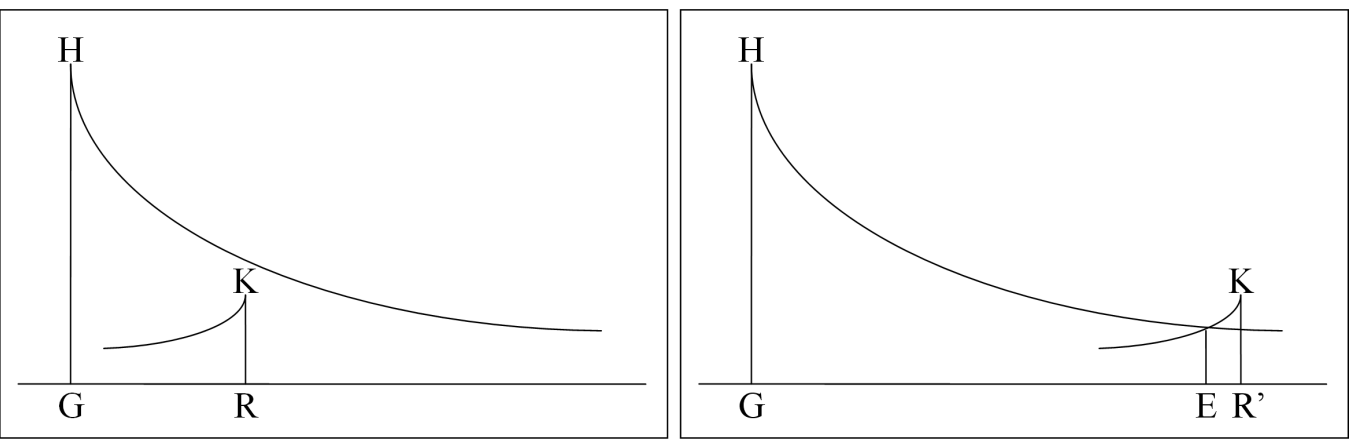
Figure 10: One half of the LSG, using number of incidences of conflict for an inverse proxy for Boulding's understanding of strength

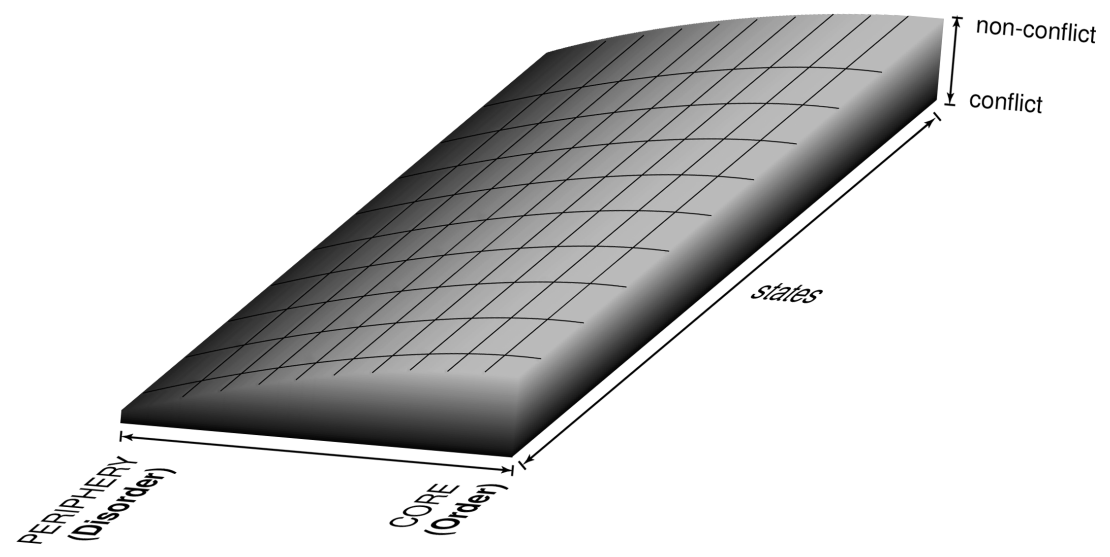

step further by integrating it into a fitness landscape. To do this, the Armed Conflict Location Event Dataset (ACLED), a PRIO data project, will be used (see Raleigh and Hegre 2005). It contains details on 4746 conflict events in 13 African states between 1960 and 2006. ${ }^{10}$ Each of these conflicts has been geo-coded with latitude and longitude variables, 97 per cent of which are accurate to the village level. By calculating the distance of each of these conflict events from the capital city of the state in which it is located, we can make some observations about the extent of government control within the state. If we follow Buhaug's (forthcoming) lead and apply the LSG on an intrastate basis, we may expect the state's power to be greatest at the capital city and weakest in those parts of the state furthest from the capital city. To do this, the number of conflict events for each state in ACLED can be used as an inverse proxy for strength and order: the more conflict events, the less strength and more disorder. This works slightly differently from Buhaug's application; instead of giving separate gradients for the government and rebel groups, only one line is used, representing the government's ability to control. In theory, the government should be most able to exercise its control (and thus retain order) at the core/capital. Disorder should be greatest at the periphery. Incidences of conflict, then, may be used to demonstrate disorder. Given these expectations and applying them in a linear fashion to a fitness landscape results

\footnotetext{
${ }^{10}$ More data items on more states are now becoming available. See the ACLED website, ,http://www. acleddata. com, for the most recent version of the dataset.
} 
Figure 11: ACLED data applied to a simple fitness landscape

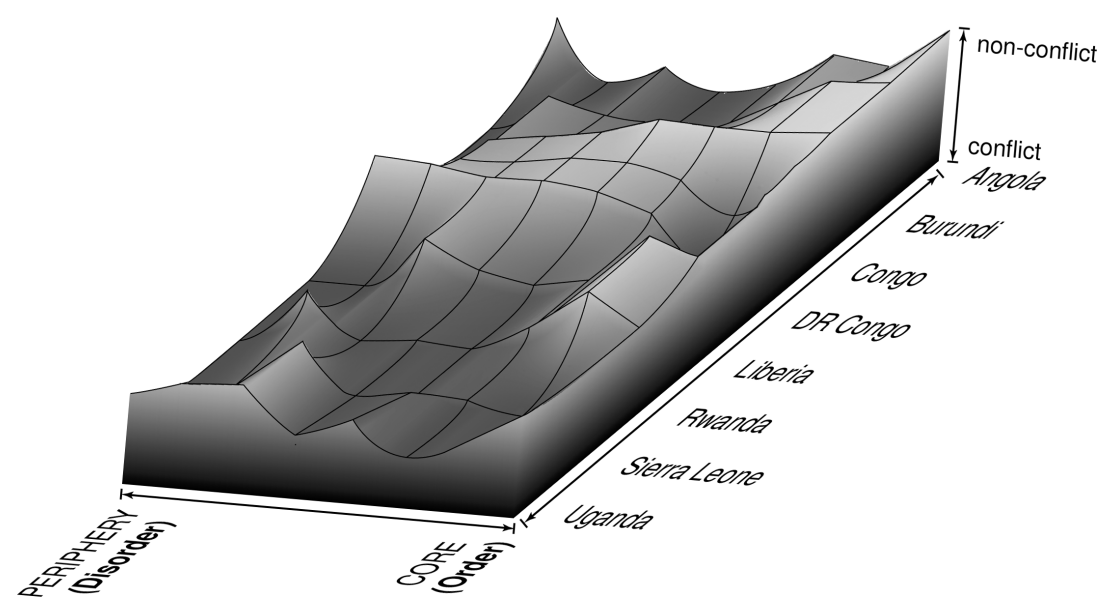

in an idealized three-dimensional version of one-half ${ }^{11}$ of Boulding's LSG (Figure 10).

On the $X$ axis we have a range between the seat of government on the righthand side (the core, representing order and control) and the state periphery (representing disorder and lack of control) on the left. The $Y$ axis is the level of conflict: down is more conflict; up is less conflict. ${ }^{12}$ The $Z$ axis represents the various states. By using a fitness landscape in this way, we are able to control for state shape and size: all states become equal.

Interestingly and unsurprisingly, when we apply the data from ACLED ${ }^{13}$ it generates a very different fitness landscape than what was expected in our idealized linear Boulding LSG model (see Figure 11).

As we can see, this is very different from the fitness landscape presented in Figure 10. In some instances, conflict is greatest in the capital; in some it is greatest at the periphery; overall, no clear pattern emerges. However, a number of core points can be made.

- Linear models of power and conflict (like the LSG) must be used very carefully and with a full recognition of their distorting character.

\footnotetext{
${ }^{11}$ Like Buhaug, we have chosen to present only one-half of the LSG. The methods used to create these fitness curves would make the other half of the diagram inappropriate.

${ }^{12}$ This is in line with our earlier decision to equate up with fitness and down with lack of fitness. Again, the reverse would be equally valid.

${ }^{13}$ Eight of the 13 ACLED states have been selected for this figure because they suffered more incidences of conflict. The states have been ordered alphabetically.
} 
- Visualizations have an impact beyond their academic meaning. Simplified visualizations like the 'dodgy dossier' will have a tendency to simplify and polarize discussions and debates about complex international situations. This may be politically expedient for some actors, but has the potential of leading international policy actors (and the public) into extremely problematic contexts and situations.

- The nature of conflict is multi-faceted even when one looks at it from a simplified LSG framework.

- Concepts of time and change are essential. Figure 11 is a representation of the fitness landscape for the period 1960-2006. There is no guarantee that a similar landscape would emerge in a subsequent period.

- Like all complex interactions, conflict exhibits both orderly and disorderly elements. Degrees of probability are the best that one can hope to achieve. A complexity perspective implicitly recognizes this uncertainty, and its tools allow us to visualize it.

- Finally, there are a whole range of interesting implications from these data and visualizations (such as comparing larger time frames, different country combinations, different regions, etc) which we have not explored in this article. Subsequent work is obviously required.

\section{Conclusion}

The main thrust of this article has not been to restate the arguments for complexity or its general relevance to IR, but to examine the relevance and efficacy of two conceptual tools of complexity on two sub-fields of IR. From the discussion above, complexity tools such as fitness landscapes and range of complexity outcomes are relevant and, with their visual power, can have a significant impact on how policy actors and the public interpret development policy and policies towards conflict areas. In both cases, under traditional IR approaches the tendency was to use linear tools to create simplified yes/no, right/wrong outcomes that projected a sense of mechanical dynamics that had a particular endpoint and should be directed by appropriate technical elites/experts. From a complexity perspective, it is both misguided and dangerous to use linear tools to analyse evolving and emergent complex systems and situations. 
Finally, we believe that these complexity conceptual tools will be relevant to other sub-disciplines in IR, since most international policy areas exhibit elements of complexity and complex dynamics and it is only with a full understanding of complexity that reasonable policy outcomes can be achieved. However, further studies are needed to confirm this belief. In essence, if the complexity-inspired 'fifth debate' in IR (as Kavalski put it) is to progress, the strategy of exploring the relevance and efficacy of complexity tools on IR sub-disciplines must continue.

\section{References}

Axelrod, Robert (1997) Complexity of cooperation: agent based models of competition and collaboration (New York: Princeton University Press)

Axelrod, Robert (2006) The evolution of cooperation (New York: Basic Books)

Beinhocker, Eric (2007) The origin of wealth: evolution, complexity, and the radical remaking of economics (New York: Random House)

Bernstein, Steven et al (2000) 'God gave physics the easy problems: adopting social science to an unpredictable world', European Journal of International Relations, 6:1, 43-76

Blackman, Tim (2001) 'Complexity theory and the new public management', Social Issues, 1:2, ,http://www.whb.co.uk/socialissues/tb.htm, accessed 2 March 2011

Boulding, Kenneth (1962) Conflict and defense: a general theory (New York: Harper Torchbooks)

Bremer, Stuart A (1992) 'Dangerous dyads: conditions affecting the likelihood of interstate war, 1816-1965', Journal of Conflict Resolution, 36:2, 309-341

Briggs, J and FD Peat (1990) Turbulent mirror: an illustrated guide to chaos theory and the science of wellness (New York: Harper \& Row)

British Government (2002) Iraq's weapons of mass destruction: the assessment of the British government (London: Stationery Office)

Buhaug, Halvard (forthcoming) 'Dude, where's my conflict? LSG, relative strength, and the location of civil war', Conflict Management and Peace Science

Buhaug, Halvard and Scott Gates (2002) 'The geography of civil war', Journal of Peace Research, 39:4, 417-433

Burchill, Scott et al (2001) Theories of international relations (New York: Palgrave) 
Cederman, Lars-Erik (1997) Emergent actors in world politics: how states and nations develop and dissolve (Princeton, NJ: Princeton University Press)

Chang, Ha-Joon (2007) Bad Samaritans: rich nations, poor policies and the threat to the developing world (New York: Random House)

Cîndea, lon (2006) 'Complex systems-new conceptual tools for international relations', Perspectives, 14:1, 46-68 Clausewitz, General Carl von (1968) On war, transl Colonel JJ Graham (London: Routledge \& Kegan Paul)

Cobb, Roger Wand Charles Elder (1970) International community: a regional and global study (New York: Holt, Rinehart \& Winston)

Comfort, Louise (2000) 'Disaster', Cambridge Review of International Affairs, 14:1, 277-294

Coveney, P and R Highfield (1995) Frontiers of complexity: the search for order in a chaotic world (London: Faber \& Faber)

Dollar, David and Jakob Svensen (1998) 'What explains the success or failure of structural adjustment programs?', World Bank Policy Research Working Paper 1938, http://papers .ssrn. com/sol3/papers . cfm?abstract_ id $=569231$.

Easterly,William (2006) The white man's burden: why the West's efforts to aid the rest have done so much ill and so little good (London: Penguin)

Gaddis, John L (2002) The landscape of history: how historians map the past (Oxford: Oxford University Press)

Gell-Mann, M (1994) The quark and the jaguar (Boston: Little, Brown)

George, Susan (1991) The debt boomerang: how Third World debt harms us all (London: Pluto Press)

Geyer, Robert (2003a) 'European integration, the problem of complexity and the revision of theory', Journal of Common Market Studies, 41:1, 15-35

Geyer, Robert (2003b) 'The end of globalisation and Europeanisation, rise of complexity and future of Scandinavian exceptionalism', Governance, $16: 4,559-577$

Geyer, Robert and Samir Rihani (2010) Complexity and public policy: a new approach to 21 st century politics, policy and society (London: Routledge)

Gleditsch, Kristian S and Michael Ward (2001) 'Measuring space: a minimum-distance database and applications to international studies', Journal of Peace Research, 38:6, 739-758

Hegre, $\mathrm{Ha}^{\circ}$ vard (2008) 'Gravitating toward war: preponderance may pacify, but power kills', Journal of Conflict Resolution, 53:4, 566-589 
Hoffman, Matthew and John Riley (2002) 'The science of political science', New Political Science, 24:4, 302-320

Hughes, Barry B (1972) 'Transaction data and analysis: in search of concepts', International Organization, 26:4, 659-680

Isard, Walter (1956) Location and space-economy: a general theory relating to industrial location, market areas, land use, trade, and urban structure (Cambridge, MA: MIT Press)

Jervis, R (1998) System effects (Princeton, NJ: Princeton University Press)

Johnston, Alastair (2005) 'Towards mid-range theorizing', International Organization, 59:4, 1013-1044

Kauffman, Stuart (1995) At home in the universe: the search for the laws of self-organization and complexity (London: Viking)

Kavalski, Emilian (2007) 'The fifth debate and the emergence of complex international relations theory: notes on the application of complexity theory to the study of international life', Cambridge Review of International Affairs, 20:3, 435-454

Kennan, George F (1961) Russia and the West under Lenin and Stalin (London: Hutchinson)

Knudsen, Torbjørn (1997) A history of international relations, 2nd edn (Manchester: Manchester University Press)

Kosack, Stephen, Gustav Ranis and James Vreeland (eds) (2005) Globalization and the nation state: the impact of the IMF and the World Bank (London: Routledge)

Krasner, Stephen D (2004) 'Sharing sovereignty: new institutions for collapsed and failing states', International Security, 29:2, 85-120

Merritt, Richard L and Caleb M Clark (1977) 'An example of data use: mail flows in the European balance of power, 1890-1920' in Karl W Deutsch, Bruno Fritsch, Helio

Jaguaribe and Andrei S Markovits (eds) Problems of world modeling: political and social implications (Cambridge, MA: Ballinger), 169-205

Mitleton-Kelly, Eve (2003) Complex systems and evolutionary perspectives on organisations: the application of complexity theory to organisations (London: Pergamon)

Moses, Jonathon and Torbjørn Knudsen (2007) Ways of knowing: competing methodologies in social and political research (New York: Palgrave)

Murdoch, James C and Todd Sandler (2004) 'Civil wars and economic growth: spatial dispersion', American Journal of Political Science, 48:1, 138-151

O'Loughlin, John (2000) 'Geography as space and geography as place: the divide between political science and political geography continues', 
Geopolitics, 5, 126-137

Power, M (1997) The audit society: rituals of verification (Oxford: Oxford University Press)

Raleigh, Clionadh and $\mathrm{Ha}^{\circ}$ vard Hegre (2005) 'Introducing ACLED: an armed conflict location and event dataset', paper presented to the conference on 'Disaggregating the

Study of Civil War and Transnational Violence', University of California Institute of Global Conflict and Cooperation, San Diego, 7-8 March

Rihani, S (2002) Complex systems theory and development practice: understanding non-linear realities (London: Zed Books)

Robst, John, Solomon Polachek and Yuan-Ching Chang (2007) 'Geographic proximity, trade, and international conflict/cooperation', Conflict Management and Peace Science, 24, 1-27

Rosenau, James (2003) Distant proximities: dynamics beyond globalization (New York: Princeton University Press)

Rostow, W (ed) (1963) The economics of take-off into sustained growth (New York: Macmillan)

Rostow, Walter (1971) Politics and the stages of growth (Cambridge: Cambridge University Press)

Rostow, Walter (1990) The stages of economic growth: a non-communist manifesto, 3rd edn (Cambridge: Cambridge University Press)

Scott, J (1998) Seeing like a state (New Haven: Yale University Press)

Spykman, Nicholas John (1942) America's strategy in world politics: the United States and the balance of power (New York: Harcourt, Brace)

Sun, Tzu (1963) The Art of War (Oxford: Oxford University Press)

Tinbergen, Jan (1962) Shaping the world economy: suggestions for an international economic policy (New York: Twentieth Century Fund)

Tinbergen, Jan (1965) International Economic Integration, 2nd rev edn (Amsterdam: Elsevier)

Tufte, Edward (1990) Envisioning information (Cheshire, CT: Graphics Press)

Urry, John (2003) Global complexity (Cambridge: Polity Press)

Wesley, James Paul (1962) 'Frequency of wars and geographical opportunity', Journal of Conflict Resolution, 6:4, 387-389

Wohlstetter, Albert (1968) 'lllusions of distance', Foreign Affairs, 46:2, 242-255

World Commission on Environment and Development (1987) Our common future (Oxford: Oxford University Press)

Zipf, George Kingsley (1949) Human behavior and the principle of least effort: an introduction to human ecology (New York: Hafner) 